\title{
Temporal and spatial determinants of route selection in homing seabirds
}

\author{
Kozue Shiomi ${ }^{\mathrm{a}, *}$, Katsufumi Sato ${ }^{\mathrm{a}}$, Nobuhiro Katsumata ${ }^{\mathrm{b}}$ and Ken Yoda $^{\mathrm{c}}$ \\ a Atmosphere and Ocean Research Institute, University of Tokyo, 5-1-5 Kashiwanoha, \\ Kashiwa, Chiba 277-8564, Japan \\ b National Research Institute of Far Seas Fisheries, Fisheries Research Agency, 5-7-1 Orido, \\ Shimizu-ku, Shizuoka 424-8633, Japan \\ ${ }^{c}$ Graduate School of Environmental Studies, Nagoya University, Furo-cho, Chikusa-ku, \\ Nagoya 464-8601, Japan \\ * Corresponding author's current address: National Institute of Polar Research (NiPR), 10-3 \\ Midori-cho, Tachikawa, Tokyo 190-8518, Japan, e-mail: shiomikozue@gmail.com
}

Received 29 January 2019; initial decision 25 March 2019; revised 15 April 2019; accepted 24 April 2019; published online 10 June 2019

\begin{abstract}
Time of day is recognized as an important behaviour modulator of wild animals mainly via physical environmental changes such as temperature and light intensity. These temporal factors can also affect animal movements (i.e., changes of locations) and consequent distribution. However, while it is commonly observed in diverse taxa that an animal's attendance at a specific site concentrates within a narrow time window, how time influences the route selections of traveling animals in the course of their movements through to the end point is still not well understood. In this study, we quantified temporal and spatial patterns in the homing paths of streaked shearwaters Calonectris leucomelas, which are present at the breeding colony exclusively after sunset, to investigate how time constrains their movement strategy for homing from at-sea foraging areas. We tracked the foraging trips using GPS loggers in chick-rearing seasons for five years. In addition, in one year we conducted displacement experiments, releasing birds at sea at three different times of the day (midday, sunset and night-time) to impose time constraints on homeward movements. The movement paths revealed that the time of sunset was key to their decision of timing and in route selections during homing. Most birds returning from foraging trips reached the coastal area around sunset by adjusting travel timing and directions, despite variation in foraging areas, and flew along the coastline to the breeding island. Meanwhile, most birds released offshore stopped flights around sunset and waited on the water surface for sunrise before restarting their homeward movements. Birds therefore avoid offshore traveling at night, appearing to preferentially use diurnal cues for homing at sea. This study demonstrates the importance of timing as well as geographic features
\end{abstract}


for homing decisions of streaked shearwaters and confirms that both spatial and temporal cognitive abilities are well developed in seabirds.

\section{Keywords}

GPS, homing, movement, navigation, seabird, shearwater, temporal cognition.

\section{Introduction}

Organisms living on the earth are inevitably exposed to diel changes of environmental conditions such as light intensity and temperature. Changes in physical environments accordingly alter biological environments for each species such as distributions of prey and predators (Helm et al., 2017). Therefore, time of day is a universal element that shapes many of the behavioural patterns observed in animals.

A variety of species have been reported to show time-specific links to certain places, such as twilight-hour departures/arrivals at nests or in foraging areas; e.g., ants (Narendra et al., 2010); fish (Hobson, 1972); birds (Rodway \& Cooke, 2001; Bijlsma \& van den Brink, 2005); and bats (Davis et al., 1962). These time-specific links are interpreted as adaptations for efficient foraging and predator avoidance. However, it is not yet well understood how time of day specifically constrains animal pathways (i.e., spatial positions over time) as traveling animals move towards a goal.

In some seabirds of the families Procellariidae (e.g., shearwaters, petrels) and Alcidae (e.g., auklets), arrivals of breeding birds at the colony at the end of foraging trips are restricted to night periods, which is considered as avoidance of diurnal predators (Cody, 1973; Harris, 1974; Rubolini et al., 2015). Those birds return near the breeding colony primarily within several hours around sunset; e.g., Manx shearwater Puffinus puffinus (Matthews, 1953); Leach's storm petrel Oceanodroma leucorhoa (Harris, 1974); Rhinoceros auklet Cerorhinca monocerata (Watanuki, 1990); Scopoli's shearwater Calonectris diomedea (Rubolini et al., 2015). In addition, previous studies on streaked (Calonectris leucomelas) and Scopoli's shearwaters, demonstrated that they timed the start of their homeward movements in accordance with the time required to reach the colony from each foraging site, engaging in the homing trajectory earlier in the day when foraging further from the colony (Shiomi et al., 2012; Padget et al., 2017). As the distance travelled to the foraging areas ranges widely between trips, and is up to $600 \mathrm{~km}$ from the colony, the onset time of homing also differs between trips by up to 20 hours. This 
variable timing behaviour results in arrivals at the breeding island within a consistent time window after sunset in any foraging trip (Shiomi et al., 2012).

The results from the two Calonectris species illustrate how the time of day influences the decision to begin homeward movements. However, why the birds adjust the onset time of homing so that their arrival time around the breeding colony is not affected by the distance to foraging areas is unknown. To examine this question, we analysed temporal and spatial patterns of homeward movements in streaked shearwaters breeding in the northeast of Japan. Data analyses particularly focused on the relationship between time of day and the birds' route selection on the way of home. Movement paths during foraging trips were recorded over five consecutive breeding seasons to observe homing patterns under natural conditions. In addition, we conducted displacement experiments in which birds were released at the same position offshore but at different times of the day (midday, sunset, and night-time) to examine the effects of forced time constraints on their homing behaviours.

\section{Materials and methods}

\subsection{GPS deployment to record foraging trips}

Streaked shearwaters breed on islands in East and Southeast Asia (Oka, 2004). As many seabirds do, they regularly commute between their breeding colonies and productive foraging areas over several hundreds of kilometres (Shiomi et al., 2012; Yoda et al., 2014; Matsumoto et al., 2017). To record foraging trips of streaked shearwaters, GPS deployments were carried out during the chick-rearing period in late August and September over 5 years from 2008 to 2012. Individual birds were selected from two breeding colonies in the northeast of Japan: Sangan Island $\left(39^{\circ} 18^{\prime} \mathrm{N}, 141^{\circ} 59^{\prime}\right.$ E; 2008) and Funakoshi-Ohshima Island (39 $24^{\prime}$ N, $141^{\circ} 59^{\prime}$ E; 2009-2012) (Figure 1). The study birds $(N=14,19,15,20$, and 16 birds in the years 2008, 2009, 2010, 2011, and 2012, respectively) were hand-caught in their nest burrows, and GPS loggers (deployment mass ca. $25 \mathrm{~g}$; TechnoSmArt, Guidonia Montecelio, Italy) were attached to their back feathers using waterproof tape (Tesa, Hamburg, Germany). Instant glue (Loctite, Düsseldorf, Germany) was supplementary used to prevent the Tesa tape from detaching. The whole mass of the loggers was on average $4.5 \%$ of the birds' body mass (range $3.5-5.7 \%$ ). Our previous study showed that the survival ratio 
of chicks until the late chick-rearing season (October) was not significantly different between control nests and those of GPS-tagged birds (Yoda et al., 2014). The loggers recorded their position every $10 \mathrm{~s}, 20 \mathrm{~s}$, or $1 \mathrm{~min}$. After a deployment period of 4-28 days, the birds were caught again at the colony, and the loggers were removed.

\subsection{Displacement experiment}

To impose time constraints on homing paths experimentally, a displacement experiment was performed during the chick-rearing period in 2011. Fifteen breeding birds were caught at the nest at night, and GPS loggers were attached to their back feathers as described above. All birds were kept separately in plastic boxes $(17.5 \times 34 \times 26 \mathrm{~cm})$, which were made to allow the birds to sit in a normal posture. There were holes on the top and bottom of the box, facilitating air changes, breathing, and removal of faeces. The birds were taken out to sea to the southeast, ca. $130 \mathrm{~km}$ from the island and ca. $100 \mathrm{~km}$ from the nearest coast of the mainland $\left(38^{\circ} 24^{\prime} \mathrm{N}, 142^{\circ} 50^{\prime} \mathrm{E}\right.$; Figure 1d-f) using a research vessel of the Japan Agency for Marine-Earth Science and Technology (Tansei-maru, KT-11-21). The displacement from the breeding island to the release point took about 7 hours. The birds were divided into three groups, each composed of five birds. One group was released around midday, one around sunset, and one at night (about $2 \mathrm{~h}$ after sunset) (Table 1). The birds were released individually after each released bird disappeared from our view. Elapsed time from capture to release for each bird was between 15.9 and $22.3 \mathrm{~h}$ (Table 1). The release day was during a new moon (29.3-day-old moon). On the night of the release day, we started to search for and recapture the birds at the colony to recover the GPS loggers.

\subsection{Data processing and analyses}

GPS location data were analysed using MATLAB (Mathworks, Natick, MA, USA). All positional fixes were mapped using the Universal Transverse Mercator (UTM) coordinate system. The positions were then subsampled using the interpl function for linear interpolation so that time intervals between fixes were adjusted to be just $1 \mathrm{~min}$ to account for the variation in the recording intervals. Horizontal ground speed was calculated from each pair of consecutive positional fixes. Following a previous study (Shiomi et al., 2012), speeds faster than $15 \mathrm{~km} / \mathrm{h}$ were considered to indicate 'flight', while those slower than $15 \mathrm{~km} / \mathrm{h}$ indicated 'floating/drifting on the water surface'. 
(a)

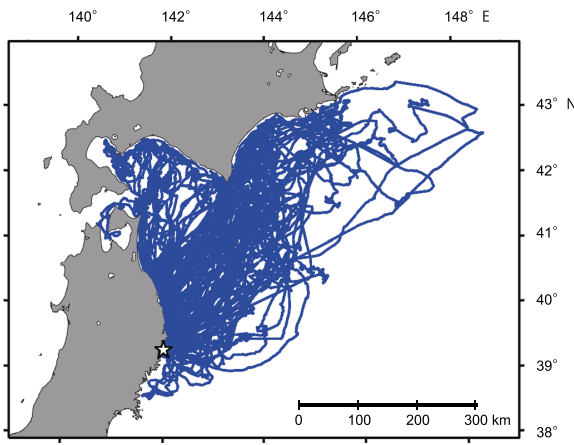

(b)

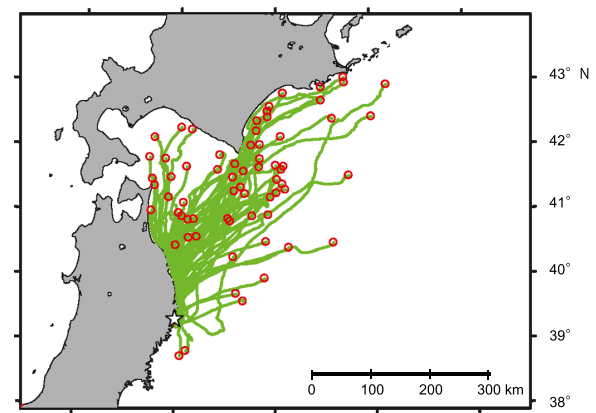

(c)

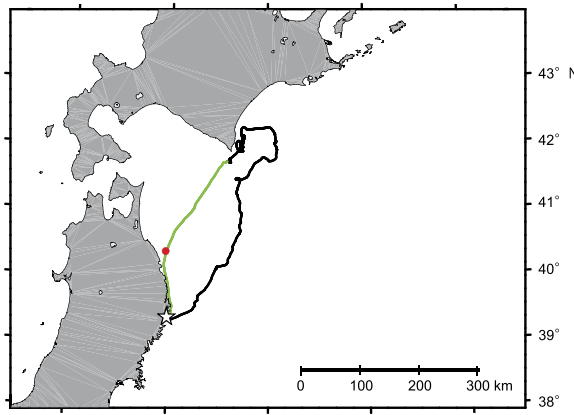

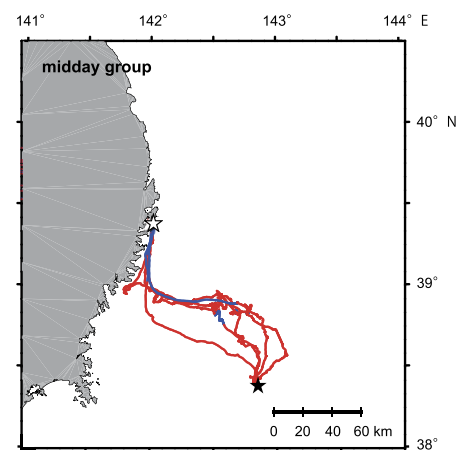

(e)

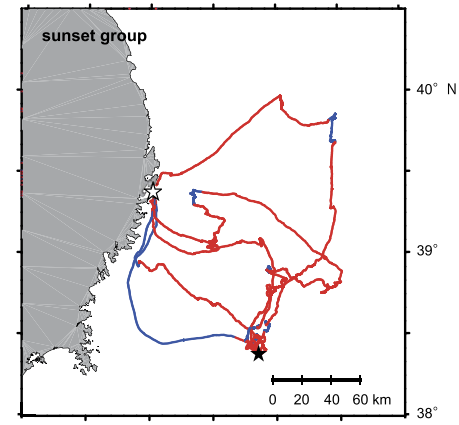

(f)

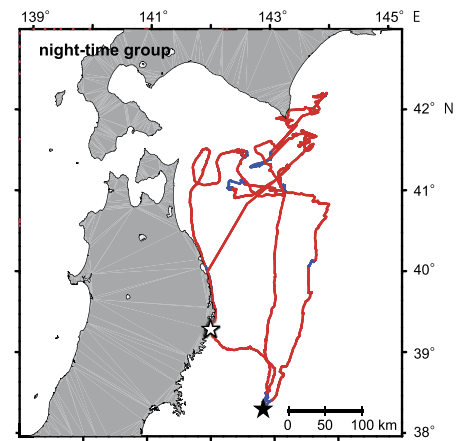

Figure 1. (a) Paths of 'long' trips of streaked shearwaters recorded using GPS loggers $(N=67$ trips). Stars indicate the area of the two breeding islands, which are close (about $11 \mathrm{~km}$ apart). (b) Homing paths of the long trips displayed in (a). Red open circles indicate the start point of each homing trip. (c) A homing path (green line) of a long trip exemplifying arrival at the coast around sunset. A red dot shows the bird's position at sunset. (d-f) Homing paths in the displacement experiment. Birds were released around (d) midday, (e) sunset and (f) at night ( $N=5,5$ and 3 birds, respectively). The black star represents the release point, and the white star represents the breeding island. Red lines indicate paths during the day, and blue lines paths at night (between $1 \mathrm{~h}$ after sunset and $1 \mathrm{~h}$ before sunrise). Note that the map scale in (f) is different from that in (d) and (e). 
Table 1.

Summary of homing behaviours in birds displaced and released at sea.

\begin{tabular}{lllccrrr}
\hline ID & Sex & $\begin{array}{l}\text { Release time of } \\
\text { day (local time } \\
\text { hh:mm) }\end{array}$ & $\begin{array}{c}\text { Elapsed } \\
\text { time from } \\
\text { capture to } \\
\text { release (h) }\end{array}$ & $\begin{array}{c}\text { Number of } \\
\text { nights } \\
\text { spent until } \\
\text { arrival }\end{array}$ & $\begin{array}{c}\text { Hours } \\
\text { taken until } \\
\text { arrival (h) }\end{array}$ & $\begin{array}{c}\text { Flight } \\
\text { duration } \\
\text { (h) }\end{array}$ & $\begin{array}{c}\text { Travel } \\
\text { distance } \\
\text { (km) }\end{array}$ \\
\hline A1 & F & Midday 12:22 & 16.1 & 1 & 31.4 & 8.5 & 199.3 \\
A2 & F & Midday 12:28 & 16.0 & 1 & 30.2 & 7.6 & 207.8 \\
A3 & M & Midday 12:32 & 15.9 & 1 & 31.1 & 8.0 & 220.2 \\
A4 & M & Midday 12:25 & 16.0 & 0 & 7.7 & 4.3 & 151.4 \\
A5 & F & Midday 12:17 & 16.1 & 0 & 13.2 & $>5.2$ & $>166.0$ \\
B1 & F & Sunset 18:04 & 21.3 & 0 & 5.9 & 5.2 & 185.7 \\
B2 & M & Sunset 18:00 & 21.3 & 1 & 24.5 & 6.4 & 192.0 \\
B3 & F & Sunset 18:07 & 21.2 & 2 & 48.6 & 11.0 & 312.4 \\
B4 & M & Sunset 18:10 & 21.1 & 1 & 27.8 & 7.9 & 221.2 \\
B5 & F & Sunset 18:12 & 20.2 & 3 & 70.9 & 16.9 & 425.6 \\
C1 & F & Night-time 20:11 & 22.2 & 3 & 74.4 & 34.4 & 936.2 \\
C2 & M & Night-time 20:31 & 22.3 & 1 & 19.3 & 5.7 & 157.1 \\
C3 & M & Night-time 20:34 & 21.8 & 6 & 142.7 & 54.3 & 1527.0 \\
\hline
\end{tabular}

Values of flight duration and travel distance marked with ' $>$ ' could not be calculated accurately because the paths were not recorded during several hours after the bird's release.

Time of sunset (i.e., when the top of the sun was on the horizon) at the colony, was obtained for each of the dates corresponding to the end of each trip using the 'suncycle' function downloaded from the website of the Scripps Institution of Oceanography, University of California, San Diego, CA, USA (http:// mooring.ucsd.edu/software/matlab/doc/toolbox/mindex_toolbox.html).

In this study, the onset of foraging trips was taken to be the point when shearwaters were further than $5 \mathrm{~km}$ from the island, and the end of foraging trips was taken to be the point when they arrived within $5 \mathrm{~km}$ of the island. We defined trips in which birds returned to the island within the first night (between sunset and sunrise) after departure as '1-day trips', and the others as 'long trips'. Trip range was calculated as the maximum distance from the colony reached in each trip. To analyse homing patterns, the homing phase was extracted for each trip. To identify the start of the return phase, we first calculated the direct distance to the island from each location, and then the rate of change in that distance over the following 1-h periods (i.e., the average approach speed for the hour during which shearwaters approached the colony). Thus, the values were negative during outward journeys and 
positive during homeward ones. The start of the homing phase for each trip was considered to occur when the average approach speed became $>15 \mathrm{~km} / \mathrm{h}$ and the distance between the corresponding position and the breeding island was further than half of the trip range.

As most birds flew along the coastline during the final homing phase (see Results), the effect of the coastline on the spatio-temporal patterns of homing was evaluated. The distance to the nearest coastline of the mainland (hereafter, coastline distance) was calculated for each location in the homing paths using latitude and longitude coordinates of the coastline obtained from the Global Self-consistent Hierarchical High-resolution Shorelines data set (GSHHS; http://www.ngdc.noaa.gov/mgg/shorelines/gshhs.html). The onset of coastal flight was taken to be from the first point after which the coastline distance became relatively constant. Specifically, the rate of change in the coastline distance over the following 1-h period was $<25 \mathrm{~km} / \mathrm{h}$ during the homing phase at a distance $>30 \mathrm{~km}$ from the nesting island. Using data gained following these definitions, the effects of darkness on movements in coastal zones, i.e., travel direction relative to the nearest coast and coastline distance during coastal flight, could be examined. Defining $R_{\text {coast }}$ as the ratio of speeds approaching the coast to ground speed, $T_{\text {coast }}$ as the arrival time at the coast, and $c_{1}-c_{4}$ as estimated constants, a sigmoid model $\left(R_{\text {coast }}=c_{1}+\right.$ $\left.c_{2} /\left(1+\exp \left(\left(c_{3}-T_{\text {coast }}\right) / c_{4}\right)\right)\right)$ was fitted using the curve fitting function of Igor Pro (WaveMetrics Inc., Lake Oswego, OR, USA). Linear mixed effect models with and without day/night effect as a fixed factor were applied to the coastline distance at the points birds crossed $40.2^{\circ} \mathrm{N}, 40.0^{\circ} \mathrm{N}, 39.8^{\circ} \mathrm{N}$, and $39.6^{\circ} \mathrm{N}$ in the final homing phase. Bird ID was included as a random factor. Akaike information criterion (AIC) values were compared between the two models to evaluate the day/night effect (Burnham \& Anderson, 2002). Model fitting was performed using the lmer function in the package lme4 (Bates et al., 2015) of $\mathrm{R}$ (version 3.2.3; $\mathrm{R}$ core Team, 2015). Values in Results are generally presented as mean $\pm \mathrm{SD}$.

All field procedures were conducted with permission from the Ministry of the Environment (No. 080605001, 85-8, 85-2, 85-6, 85-10) and Agency for Cultural Affairs (No. 4-486, 300, 245, 435, 360), Japan and were approved by the Animal Experimental Committee of the University of Tokyo (No. 17-6, P09-3, P10-6, P11-4, P12-8). 


\section{Results}

\subsection{Homing behaviours during foraging trips}

Of the 84 breeding birds tagged with GPS data loggers, 81 were recaptured at the colony 4 to 28 days after deployment. Fifty-six loggers recorded flight paths at sea, while the others failed to work $(N=15)$ or fell off $(N=10)$. In total, the loggers recorded 131 one-day trips from 49 birds and 91 long trips from 52 birds (Figure 1a). Only long trips were analysed further in this study because time allocation and homing decisions are expected to be more limited in 1-day trips (birds must travel, forage and home with $24 \mathrm{~h}$ ). In the displacement experiment, we could not capture some of the released birds on the first day following their return after release. In this case, some foraging trips were also recorded for displaced birds. Long trips recorded for these individuals were also added to the analyses of homing behaviours during foraging trips ( $N=24$ trips from 11 birds). Depending on the specific purpose of each analysis, some long trips were excluded due to phases lacking positional data. Therefore, the sample size differed among the analyses.

The average duration and range of long trips was $3.5 \pm 1.6$ days (longest 9.6 days; $N=82$ trips) and $340.1 \pm 128.0 \mathrm{~km}$ (furthest $674.3 \mathrm{~km} ; N=98$ trips), respectively. The start points of the homing phase in long trips were widely spread out and were up to circa $540 \mathrm{~km}$ from the islands (Figure 1b; $276.9 \pm 100.9 \mathrm{~km})$. In the final phase of homing, the birds commonly flew for a considerable distance and duration along the coastline, $136.6 \pm 74.9 \mathrm{~km}$ (up to $352.3 \mathrm{~km}$ ) and $4.3 \pm 2.5 \mathrm{~h}$ (up to $12.6 \mathrm{~h}$ ), respectively ( $N=59$ trips), although the start positions of the coastal flights differed among the trips (17.4 to $307.9 \mathrm{~km}$ from the breeding island). A histogram of the distance to the nearest coastline (coastline distance) showed that, in $70.1 \%$ of the trips, birds had arrived within $10 \mathrm{~km}$ of the coast by $1 \mathrm{~h}$ after the sunset, while distances from the breeding island $1 \mathrm{~h}$ after the sunset were further than $100 \mathrm{~km}$ in circa $26 \%$ of the trips (Figure $2 \mathrm{a}$ and b; $N=87$ trips). The time of day when the birds reached the coast was concentrated around sunset (Figure 2c; median $0.045 \mathrm{~h}$ after sunset). This was contrast to the islandarrival times, which were later and had no peak time (Figure 2d; median $3.7 \mathrm{~h}$ after sunset) ( $N=57$ trips). When birds reached the coast after the sunset, the ratio of speeds approaching the coast to ground speeds averaged for $3 \mathrm{~h}$ before the arrival at the coast increased (Figure 3; the obtained sigmoid 

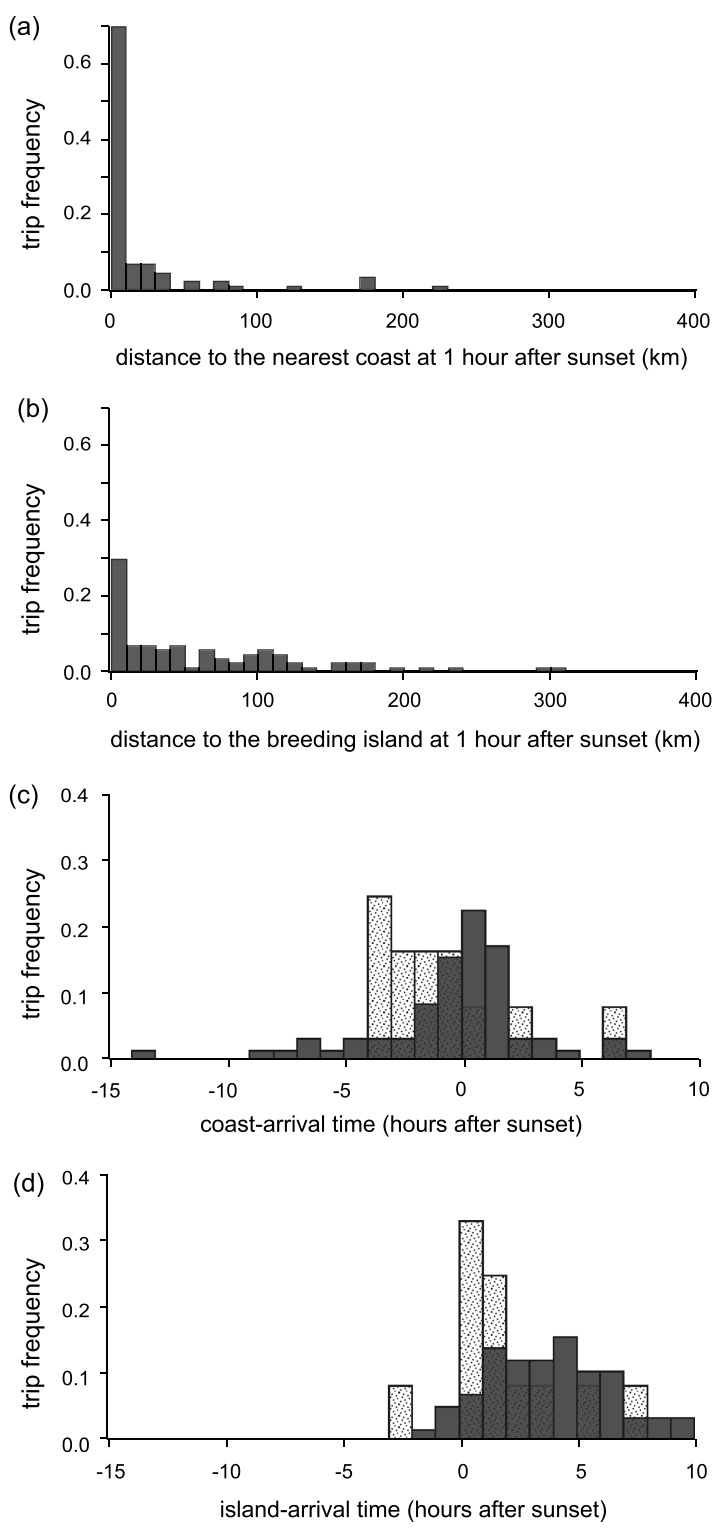

Figure 2. Histograms of (a) the distance to the nearest coast of the Japanese mainland, (b) the distance to the breeding islands $1 \mathrm{~h}$ after sunset ( $N=87$ trips), (c) the arrival times at the coast, and (d) the arrival times at the breeding island (when the birds arrived within $5 \mathrm{~km}$ of the island) during homing. In (c) and (d), grey histograms show data from foraging trips ( $N=57$ trips), and dotted histograms data of birds released at sea in the displacement experiment ( $N=11$ birds). Times are presented as time since sunset. 


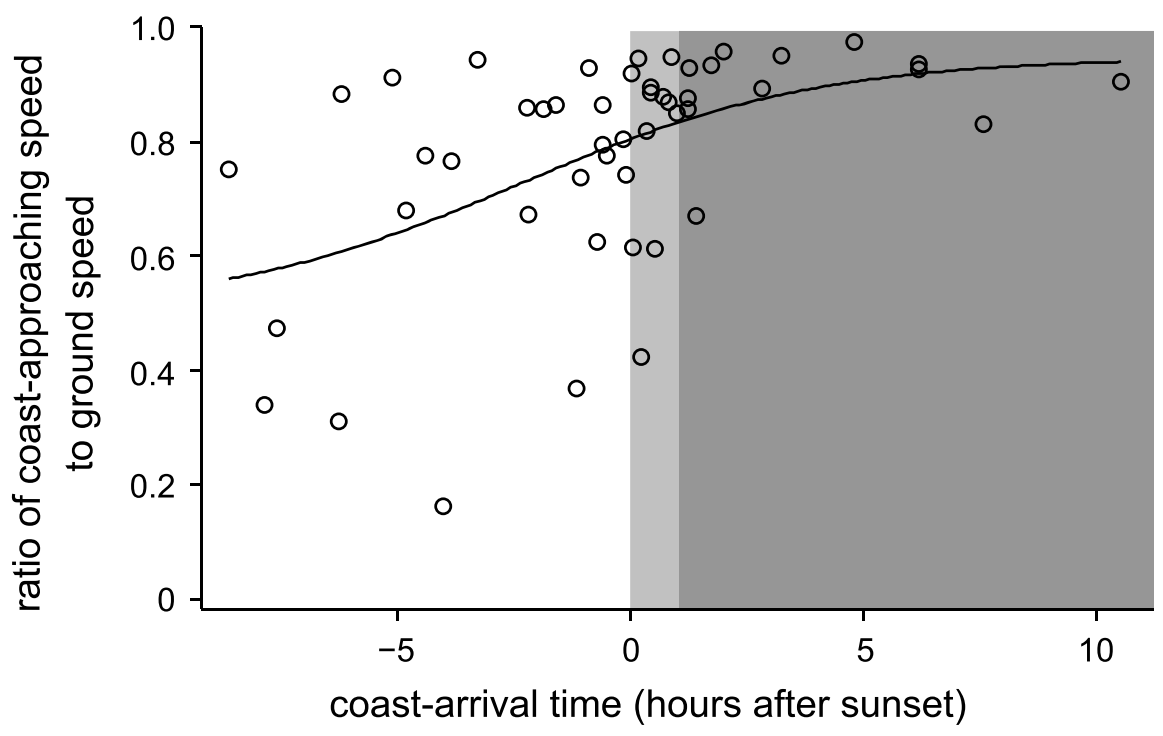

Figure 3. Relationship between the ratio of speeds approaching the coast to ground speeds and arrival time at the coast $(N=49$ trips). Times are presented as time since sunset. The dark grey zone represents night defined as times later than $1 \mathrm{~h}$ after sunset, and light grey zone the 1-hour period after sunset. The black line shows the regression line obtained by fitting a sigmoid model $(y=0.51+0.44 /(1+\exp ((-2.4-x) / 3.2)))$.

equation was $\left.R_{\text {coast }}=0.51+0.44 /\left(1+\exp \left(\left(-2.4-T_{\text {coast }}\right) / 3.2\right)\right)\right)$, indicating that the travel directions were more coast-oriented. During coastal flights, birds flew closer to the coastline at night than in daylight hours (Figure 4). AIC values of the day/night model for the coastline distance were smaller than the null model, although the difference was greater than 2 only for the distance when crossing $40.2^{\circ} \mathrm{N}$ (Table 2 ).

\subsection{Homing behaviours in displacement experiment}

Of the 15 released birds, 14 were recaptured in the colony, and their GPS loggers were retrieved. Thirteen loggers successfully recorded flight paths. According to the positional data, the first arrival dates following the release ranged from the release day to 6 days later (Table 1). Initial movement directions from the release point were always northward, but some birds of the night-released group appeared to go foraging instead of homing, resulting in relatively long duration and distance of the travel taken until returning to the nest (Table 1). 

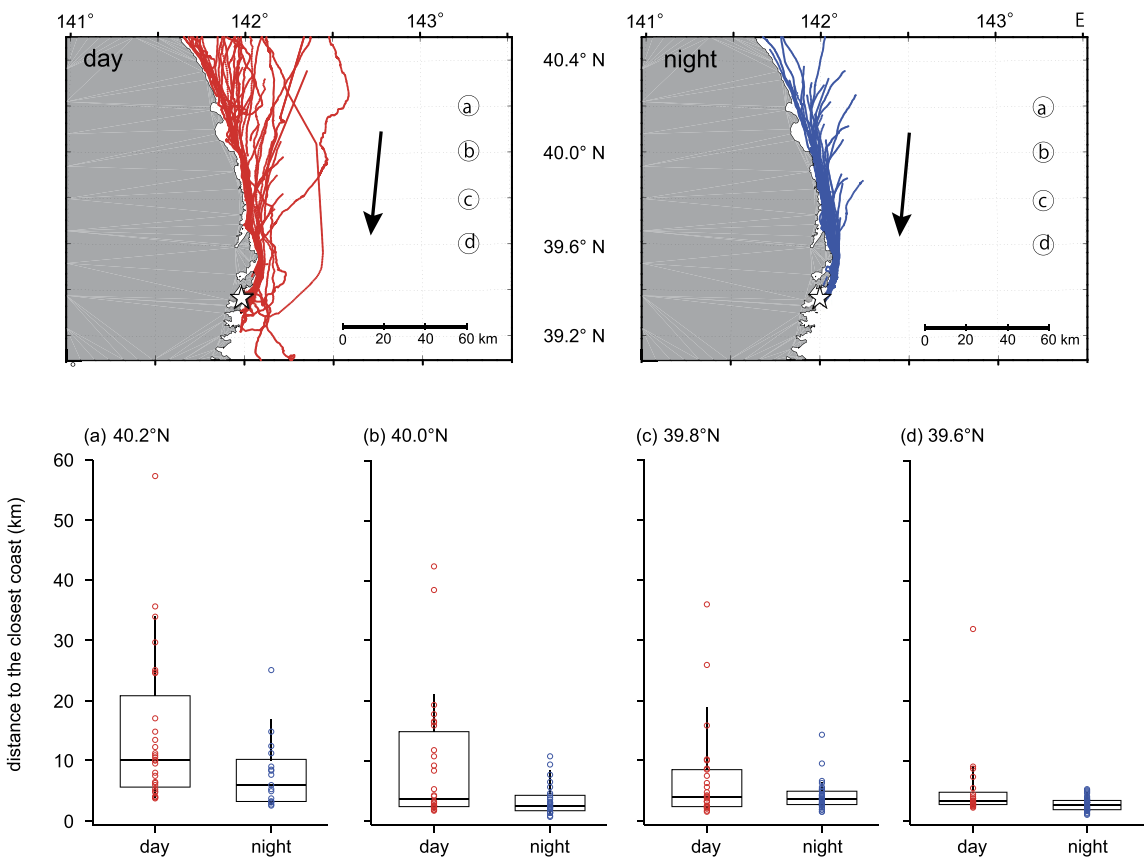

Figure 4. Movement paths during the day (red) and at night (times later than $1 \mathrm{~h}$ after sunset; blue) in the final phase of homing $(N=64$ trips). Stars indicate the area of the breeding islands. Box plots compare the distances to the nearest coastline when each bird crossed latitudinal lines of (a) 40.2, (b) 40.0, (c) 39.8 and (d) $39.6^{\circ} \mathrm{N}$. Horizontal lines within the boxes show the medians, while the upper and lower bounds of the boxes show the first and third quartiles, and the edge of the vertical lines above and below the boxes show the 10th and 90th percentiles, respectively.

\section{Table 2.}

Results of linear mixed effect model analyses of distances to the nearest coastline when each bird crossed defined latitudinal lines.

\begin{tabular}{|c|c|c|c|c|}
\hline & $\begin{array}{c}\text { (a) } \\
40.2^{\circ} \mathrm{N}\end{array}$ & $\begin{array}{c}\text { (b) } \\
40.0^{\circ} \mathrm{N}\end{array}$ & $\begin{array}{c}(\mathrm{c}) \\
39.8^{\circ} \mathrm{N}\end{array}$ & $\begin{array}{c}\text { (d) } \\
39.6^{\circ} \mathrm{N}\end{array}$ \\
\hline day/night model & 339.0 & 368.8 & 375.7 & 327.2 \\
\hline null model & 343.8 & 369.9 & 376.6 & 329.2 \\
\hline \multirow{3}{*}{$\begin{array}{ll}\Delta \mathrm{AIC}(\text { day/night model }- \text { null model }) \\
\begin{array}{ll}\text { estimate }(\mathrm{km}) & \begin{array}{l}\text { day } \\
\text { night }\end{array}\end{array}\end{array}$} & -4.82 & -1.19 & -0.93 & -1.99 \\
\hline & 14.0 & 7.7 & 6.4 & 4.6 \\
\hline & 10.5 & 6.3 & 5.1 & 3.6 \\
\hline
\end{tabular}

The difference of Akaike information criterion (AIC) values between the day/night model (distance approx. day/night) and the null model (distance approx. 1) was more than 2 only for data when crossing $40.2^{\circ} \mathrm{N}$ (a) (see also Figure 4). 
Most of the released birds flew along the coastline in the final phase of homing (Figure 1d-f). The arrivals at the coast occurred mostly by sunset, and the birds arrived at the island at night, as occurs in natural foraging trips (Figure $2 \mathrm{c}$ and $\mathrm{d}$ ). Birds arriving to the island on the next day of release or later ( $N=10$ birds) stopped traveling during the first night following release and waited on the water surface for sunrise before restarting their homeward movements. Comparing the travelled distance per hour, that of the first night (between $1 \mathrm{~h}$ after sunset and $1 \mathrm{~h}$ before sunrise) was clearly lower than the twilight periods ( $2 \mathrm{~h}$ around sunset and sunrise); $0.82 \mathrm{~km} \pm 0.56$ during the first night, versus $17.5 \mathrm{~km} \pm 3.2$ during the twilight (Figure 5).

\section{Discussion}

This study investigated homing paths in foraging trips of the chick-rearing streaked shearwaters and shearwaters artificially displaced and released at sea $130 \mathrm{~km}$ from the colony. The analyses of both spatial and temporal characteristics enabled us to clarify that the time of sunset was key to their decision of timing and in route selections for homing and that birds avoid offshore traveling at night.

As foraging areas were widely distributed, up to $670 \mathrm{~km}$ from the colony, the travel route, duration, and distance taken for homing were highly variable among the trips. However, most birds commonly travelled along the coastline in the final phase of homing. A previous study reported that the headings of homing streaked shearwaters pointed towards the coast rather than the breeding island when they travelled within $40 \mathrm{~km}$ of the coastline (Goto et al., 2017). Our results further showed that their route selection was affected not only by space but also by time: their travel direction during the few hours before reaching the coast was oriented more towards the coast when the time was close to or after sunset, as if birds were more attracted to the coastline along with changes of destination and/or navigational cues. As a result, they arrived at the mainland coast mostly around sunset, while the start points and total distances of the coastal flights to the island differed greatly among the trips. Thus, the wide coastal area of the mainland could function as a temporary destination in the process of homing, and its relative importance appears to change with time of day (Figure 6). By such adjustments in movements, the shearwaters probably avoid nocturnal offshore traveling and use the coastline as a navigational aid, particularly at night. 
(a)

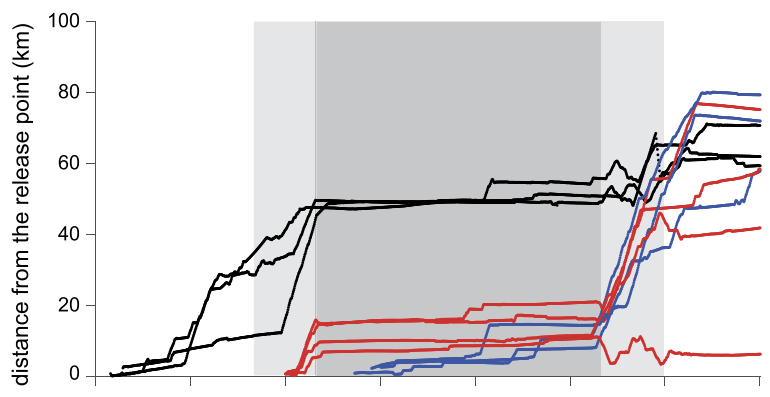

(b)
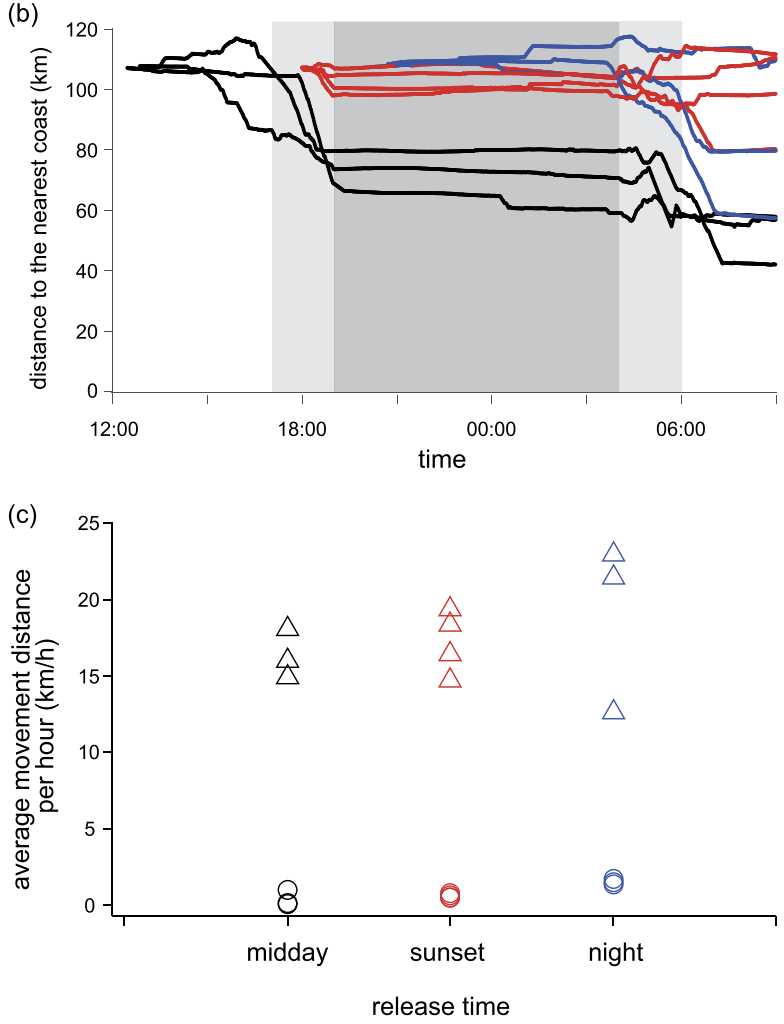

Figure 5. Time-series data of (a) the distance from the release point and (b) the distance to the breeding island for birds released around midday (black; $N=3$ birds), around sunset (red; $N=4$ birds) and at night-time (blue; $N=3$ birds). The light grey zone represents $2 \mathrm{~h}$ around sunset and sunrise, while the dark grey represents night-time. (c) Comparison of the average movement distances per hour during the first night after release (circles; dark grey zone in (a), (b)) and during dawn and dusk (triangles; light grey zone in (a), (b)) for three groups of birds released at different times of the day. 


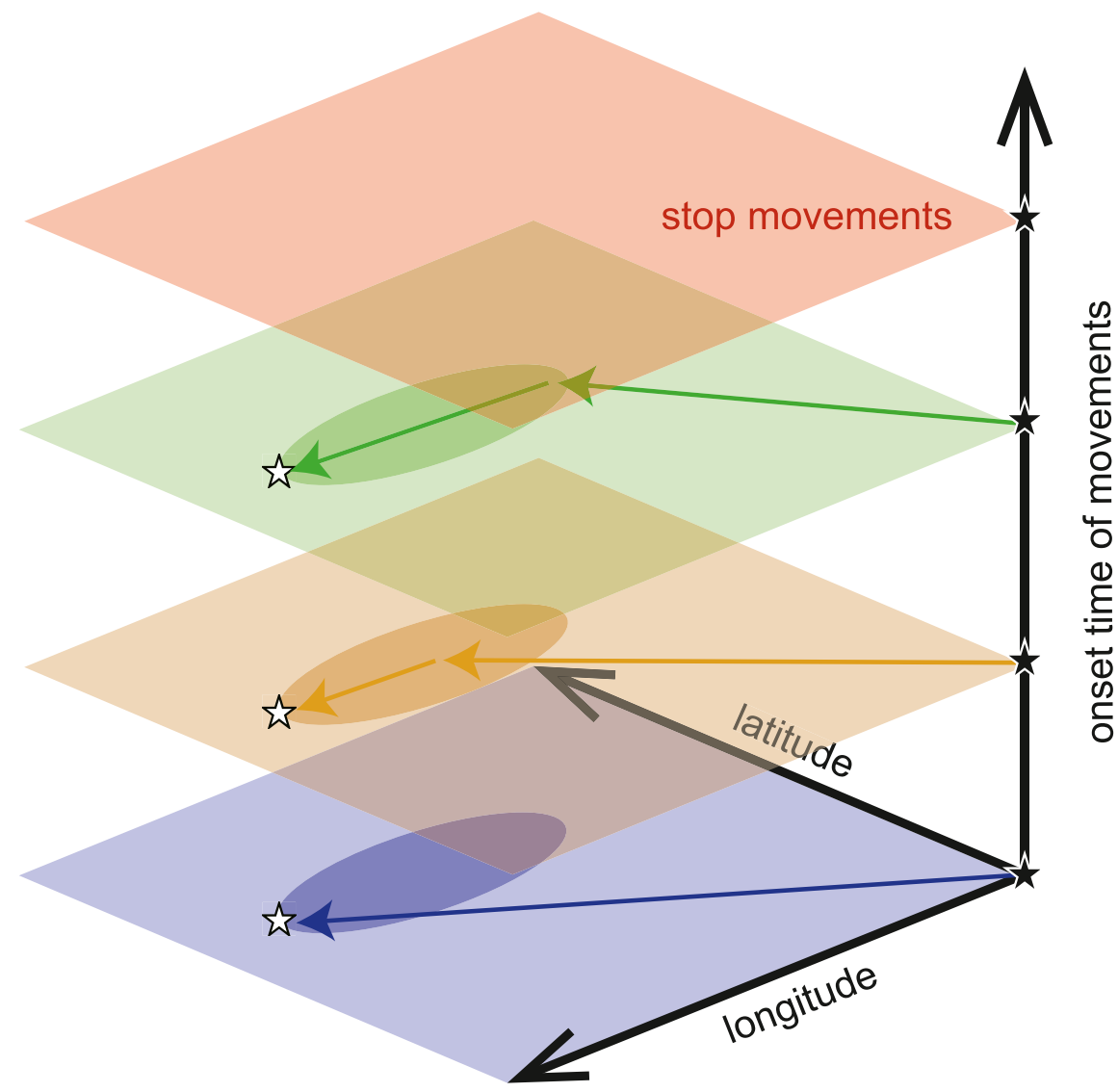

Figure 6. Conceptual diagram of temporal effects on animal movement paths based on the homing patterns found in shearwaters. Open stars indicate the destination of movements initiated at the filled stars, and ellipses indicate areas used as temporary destinations linked to the final destination. When starting a movement early enough, individuals use a straight course to their destination (blue path), but when starting a movement later, individuals use different directions to reach the closer temporary destination (orange and green paths). When it is too late to reach the temporary destination in time, animals would not start moving and wait for the opportune moment (red plane).

Displacement experiments strengthen our interpretations that the shearwaters avoided nocturnal movements at sea and used the coastline for nocturnal navigation. The birds of all three groups released offshore never headed south, which would take them away from their breeding island, mostly returning to the colony the day following release. As with the normal foraging trips, the displaced streaked shearwaters arrived at the coast and flew along 
the coastline in the final phase of the homing paths, and all returned to the island after sunset. This illustrates the tight constraints on the timing of the homing and arrival at the colony. Importantly, the released birds obviously reduced their movements at sea after sunset and started traveling again around sunrise, regardless of their release time.

When flying back to the breeding colony, birds are expected to rely on multiple environmental cues for navigation as well as for flight and body posture controls. Reliable cues may change with the combination of location and time during homing. To explain the ability of long-distance movements in the Procellariidae, the olfactory navigation hypothesis has been prevailing and supported by experiments with sensory manipulation (Gagliardo et al., 2013; Pollonara et al., 2015; Padget et al., 2017) and mathematical analyses of foraging trip tracks (Reynolds et al., 2015; Abolaffio et al., 2018). Although we cannot rule out the possibility that streaked shearwaters also rely on the similar mechanism, olfactory cues should not be dependent on time of day. It may be expected that if they primarily used olfaction to travel over seascapes they would still travel during the night. Avoidance of nocturnal offshore traveling found in streaked shearwaters implies that they usually use cues available during the day such as the sun azimuth compass (SchmidtKoenig, 1960; Padget et al. 2018) for navigation and/or visual information such as optic flow and perception of the horizon for flight and body posture controls (Lee, 1980; Schiffner \& Srinivasan, 2015) when travelling over seascapes. Once the birds reach the coastal areas following pelagic flights by sunset and choose the direction in which to proceed, they can visually follow the coastline leading to the nesting island. This view of the function of the coastline is supported by the fact that birds flew closer to the coast at night than during the day. As their visual range decreases after dark, they are expected to follow the coastline more closely during night-time.

Our results generally fit previous findings from studies of a pelagic seabird, Manx shearwater. About 65 years ago, Matthews (1953) postulated based on a displacement experiment of Manx shearwaters, although he had no technology to measure bird positions, that the longer homing durations of birds released in the late afternoon compared to those of birds released earlier may result from suspending their homeward movements until sunrise as they failed to arrive to the breeding island or a familiar coastline by sunset (Matthews, 1953). Later studies using GPS loggers showed that Manx shearwaters reduced flight time at night (Guilford et al., 2008) and indicated that 
they use a time-compensated sun compass for homeward navigation (Padget et al., 2018). Therefore, this species may use similar homing strategies as that of streaked shearwaters, i.e., completing offshore flights by sunset and using the coastline as a navigational aid for nocturnal travelling.

Previous studies clarified that shearwaters can adjust their onset time of homing according to the travel time required to return to the colony from each foraging area (Shiomi et al., 2012; Padget et al., 2017). Considering the previous and present results together, the shearwaters appear to balance the avoidance of diurnal predators on the island and foraging at sea with the avoidance of nocturnal offshore traveling by adjusting the onset timing and the routes of homing. Such a movement strategy presumably requires developed cognitive abilities around the use of both space and time. Thus, the combined effects of these ecological, geographical, and cognitive factors can shape the spatio-temporal patterns of homeward movements in breeding seabirds. It remains to be seen if movement patterns observed in our study are common in other populations of streaked shearwaters and other seabird species in general. Populations of seabirds on oceanic islands, for example, may be more constrained by time because they do not have a reliable guide after dark and need to reach the colony by sunset.

This study demonstrated that time of the day is an important constraint for the decision to home and birds displaced away from the colony engaged on a homing trip only when they could reach the colony or the coastline in the due time, otherwise preferring to remain at sea. Detailed analyses of both spatial and temporal aspects of the movement paths under natural conditions combined with an experimental approach (displacement experiments) could help us to understand potential factors affecting movement patterns of wild animals in addition to navigational ability.

\section{Acknowledgements}

We are grateful to R. Tsutsumi, C. Zavalaga, Y. Kogure, S. Machino, Y. Yonehara, C-A. Bost, G. Sakamoto and many colleagues for their field assistance and to N. Miura, Tatsuo Abe, Takanori Abe, T. Tashiro, M. Kurosawa, K. Morita, M. Hirano and other local fishermen for providing transport to the islands by boat. We thank people involved in the displacement experiments using Tanseimaru (KT-11-21) for their help and Sasaki Plastic Co., Ltd. for providing custom-made cases for the data loggers. We also thank M. Hindell 
and R.P. Wilson for their comments on the early draft and J. Semmens and two anonymous reviewers for their help to finalize the manuscript. We would like to thank Editage (www.editage.jp) for English language editing. This study was supported by Grant-in-Aid for JSPS Research Fellow (grant number 23-2916) to K. Shiomi, JSPS KAKENHI (grant numbers JP20519002, JP19255001, JP24681006, JP16H06541, JP17H05017 to K. Shiomi, K. Sato and K.Y.), the program Bio-Logging Science of the University of Tokyo, 'UTBLS' led by N. Miyazaki, an Aid fund from Meijo University to Y. Niizuma for reconstruction assistance of the Great East Japan Earthquake, and the Cooperative Program of Atmosphere and Ocean Research Institute, the University of Tokyo.

\section{References}

Abolaffio, M., Reynolds, A.M., Cecere, J.G., Paiva, V.H. \& Focardi, S. (2018). Olfactorycued navigation in shearwaters: linking movement patterns to mechanisms. - Sci. Rep. 8: 11590.

Bates, D., Mächler, M., Bolker, B.M. \& Walker, S.C. (2015). Fitting linear mixed-effects models using lme4. - J. Stat. Softw. 67: 1-48.

Bijlsma, R.G. \& van den Brink, B. (2005). A barn swallow Hirundo rustica roost under attack: timing and risks in the presence of African Hobbies Falco cuvieri. - Ardea 93: 37-48.

Burnham, K.P. \& Anderson, D.R. (2002). Model selection and multimodel inference: a practical information-theoretic approach, 2nd edn. - Springer, New York, NY.

Cody, M.L. (1973). Coexistence, coevolution and convergent evolution in seabird communities. - Ecology 54: 31-44.

Davis, R.B., Herreid, C.F. \& Short, H.L. (1962). Mexican free-tailed bats in Texas. — Ecol. Monogr. 32: 311-346.

Gagliardo, A., Bried, J., Lambardi, P., Luschi, P., Wikelski, M. \& Bonadonna, F. (2013). Oceanic navigation in Cory's shearwaters: evidence for a crucial role of olfactory cues for homing after displacement. - J. Exp. Biol. 216: 2798-2805.

Goto, Y., Yoda, K. \& Sato, K. (2017). Asymmetry hidden in birds' tracks reveals wind, heading, and orientation ability over the ocean. - Sci. Adv. 3: e1700097.

Guilford, T.C., Meade, J., Freeman, R., Biro, D., Evans, T., Bonadonna, F., Boyle, D., Roberts, S. \& Perrins, C.M. (2008). GPS tracking of the foraging movements of Manx shearwaters Puffinus puffinus breeding on Skomer Island, Wales. — Ibis 150: 462-473.

Harris, S.W. (1974). Status, chronology, and ecology of nesting storm petrels in Northwestern California. - Condor 76: 249-261.

Helm, B., Visser, M.E., Schwartz, W., Kronfeld-Schor, N., Gerkema, M., Piersma, T. \& Bloch, G. (2017). Two sides of a coin: ecological and chronobiological perspectives of timing in the wild. — Phil. Trans. Roy. Soc. Lond. B: Biol. Sci. 372: 20160246. 
Hobson, E.S. (1972). Activity of Hawaiian reef fishes during the evening and morning transitions between daylight and darkness. - Fish. Bull. 70: 715-740.

Lee, D.N. (1980). The optic flow field: the foundation of vision. — Philos. Trans. Roy. Soc. Lond. B: Biol. Sci. 290: 169-179.

Matsumoto, S., Yamamoto, T., Yamamoto, M., Zavalaga, C.B. \& Yoda, K. (2017). Sex-related differences in the foraging movement of streaked shearwaters Calonectris leucomelas breeding on Awashima Island in the Sea of Japan. — Ornithol. Sci. 16: 23-32.

Matthews, G.V.T. (1953). Navigation in the Manx shearwater. — J. Exp. Biol. 30: 370-396.

Narendra, A., Reid, S.F. \& Hemmi, J.M. (2010). The twilight zone: ambient light levels trigger activity in primitive ants. — Proc. Roy. Soc. Lond. B: Biol. Sci. 277: 1531-1538.

Oka, N. (2004). The distribution of streaked shearwater colonies, with special attention to population size, area of sea where located and surface water temperature. - J. Yamashina Inst. Ornithol. 35: 164-188.

Padget, O., Dell'Ariccia, G., Gagliardo, A., González-Solís, J. \& Guilford, T. (2017). Anosmia impairs homing orientation but not foraging behaviour in free-ranging shearwaters. — Sci. Rep. 7: 9668.

Padget, O., Bond, S.L., Kavelaars, M.M., van Loon, E., Bolton, M., Fayet, A.L., Syposz, M., Roberts, S. \& Guilford, T. (2018). In situ clock shift reveals that the sun compass contributes to orientation in a pelagic seabird. — Curr. Biol. 28: 275-279.

Pollonara, E., Luschi, P., Guilford, T., Wikelski, M., Bonadonna, F. \& Gagliardo, A. (2015). Olfaction and topography, but not magnetic cues, control navigation in a pelagic seabird: displacements with shearwaters in the Mediterranean Sea. — Sci. Rep. 5: 16486.

R Core Team (2015). R: a language and environment for statistical computing. - R Foundation for Statistical Computing, Vienna, available online at https://www.R-project.org/.

Reynolds, A.M., Cecere, J.G., Paiva, V.H., Ramos, J.A. \& Focardi, S. (2015). Pelagic seabird flight patterns are consistent with a reliance on olfactory maps for oceanic navigation. Proc. Roy. Soc. Lond. B: Biol. Sci. 282: 20150468.

Rodway, M.S. \& Cooke, F. (2001). Effect of food availability on arrival and departure decisions of Harlequin ducks at diurnal feeding grounds. - Condor 103: 870-874.

Rubolini, D., Maggini, I., Ambrosini, R., Imperio, S., Paiva, V.H., Gaibani, G., Saino, N. \& Cecere, J.G. (2015). The effect of moonlight on Scopoli's shearwater Calonectris diomedea colony attendance patterns and nocturnal foraging: a test of the foraging efficiency hypothesis. — Ethology 121: 284-299.

Schiffner, I. \& Srinivasan, M.V. (2015). Direct evidence for vision-based control of flight speed in budgerigars. - Sci. Rep. 5: 10992.

Schmidt-Koenig, K. (1960). The sun azimuth compass: one factor in the orientation of homing pigeons. - Science 131: 826-828.

Shiomi, K., Yoda, K., Katsumata, N. \& Sato, K. (2012). Temporal tuning of homeward flights in seabirds. - Anim. Behav. 83: 355-359.

Watanuki, Y. (1990). Daily activity pattern of rhinoceros auklets and kleptoparasitism by black-tailed gulls. — Ornis Scand. 21: 28-36. 
Yoda, K., Shiomi, K. \& Sato, K. (2014). Foraging spots of streaked shearwaters in relation to ocean surface currents as identified using their drift movements. - Prog. Oceanogr. 122: 54-64. 